\title{
Spatiotemporal Variations of Land Use Change in Recent Four Decades in a Typical Oasis City-Urumqi
}

\author{
LIU Bin ${ }^{1,2,3, a}$, SHI Qingdong ${ }^{* 1,3, b}$ and JIN Jia ${ }^{2, c}$ \\ ${ }^{1}$ College of Resources and Environmental Sciences, Xinjiang University, Urumqi, China \\ ${ }^{2}$ Xinjiang Institute of Ecology and Geography, Chinese Academy of Sciences, Urumqi, China \\ ${ }^{3}$ Ministry of Education Key Laboratory of Oasis Ecology of Xinjiang, Urumqi, China

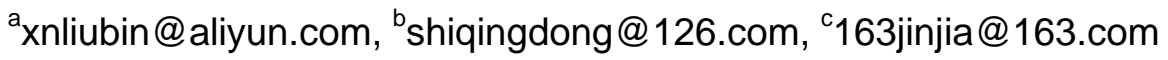

\begin{abstract}
Keywords: LUCC, Arid Land, Urumqi, Spatiotemporal Pattern, Land-use transition matrix. Abstract. Urumqi is a typical oasis city in western China. A clear understanding of Urumqi's LUCC (Land-Use and Land-Cover Change) pattern has important guiding significance to environmental improvement and socio-economic sustainable development. This paper analyzed the spatiotemporal variations of LUCC in Urumqi from 1980 to 2015 base on LUCC dataset. The results showed that the LUCC of Urumqi changed drastically from 1980 to 2015, in which the grasslands area continued to decrease and mainly converted to urban built-up lands and croplands. The area of urban and built-up lands in Urumqi had been increased nearly three times, the downtown mainly expanded towards the northward direction. The water bodies' area of Chaihuobpu Lake in the southern mountainous decreased significantly from 2010 to 2015 .
\end{abstract}

\section{Introduction}

Global climate change has a significant impact on different natural and managed ecosystems [1]. Meanwhile, the rapid development of human society threatens ecosystem security. LUCC (Land-Use and Land-Cover Change) is influenced by both natural and human activities; land-use change has been one of focused research topics in the field of global change.

Land resources are important foundation for human subsistence and development. In recent years, with the rapid expansion of population and the rapid progress of science and technology, the scope and intensity of land use by humans are also growing unprecedentedly, which leading to a series of ecological and environmental problems such as soil erosion, desertification, salinization, desertification, environmental pollution and so on. Those ecological and environmental problems impacts threat regional ecological environment security and directly affect regional and national sustainable development [2-4]. Current LUCC researches mainly focused on natural ecosystems or economically developed area and using the data for the statistical data whose sequence is shortand cannot accurately comprehend the space-time dynamic. Remote sensing (RS) technique provides a good way to understand the dynamics of the Earth's biosphere and vegetation. LUCC products based on remote sensing data are effective tools to monitor the spatial and temporal dynamics of land use change.

Urumqi City as the political, economic and cultural center of Xinjiang Uygur Autonomous Region, with the industrialization and urbanization of the rapid development, its land use and land cover types has undergone dramatic changes in the past few decades. As a typical oasis city in arid region of northwest China, Urumqi is an ecologically fragile sensitive area. Water resource is one of the major constraints in Urumqi, and drought has significant impacts on agricultural, ecological and economic development. The evolution of the natural environment has its relatively unique objective laws of operation. So a clear understanding of Urumqi LUCC's dynamic have great significance to protect land resources, improve the ecological environment, promote regional ecosystem improvement and socio-economic sustainable. 


\section{Materials and methods}

Study Area. Urumqi is a typical oasis city, which located in the northwest of China. It is not only the capital of Xinjiang Uygur Autonomous Region, but also Xinjiang's political, economic and cultural center. Urumqi located in the hinterland of the Eurasian continent as $86^{\circ} 37^{\prime} \mathrm{E} \sim 88^{\circ} 58^{\prime} \mathrm{E}$ and $42^{\circ} 45^{\prime} \mathrm{N} \sim 44^{\circ} 08^{\prime} \mathrm{N}$, where belongs to a temperate semi-arid continental climate[5-7]. At present, seven districts and one county, named the Tianshan District, Shayibake District, New-town District, Shuimogou District, Toutun River District, Dabancheng District, Midong District and Urumqi County, whom administered by Urumqi city [8]. At the end of 2015, the administrative divisions of the city area is about $4.3 \times 10^{2} \mathrm{~km}^{2}$; the total population is about $3.55 \times 10^{6}$, and the full year GDP reached $2.68 \times 10^{11}$ Yuan RMB[9]. Urumqi is the Chinese open doors in the Central Asian region, as well as an important hub in southern and northern area of traffic and second of the Eurasian Continental Bridge, which has the extremely important geographical position.

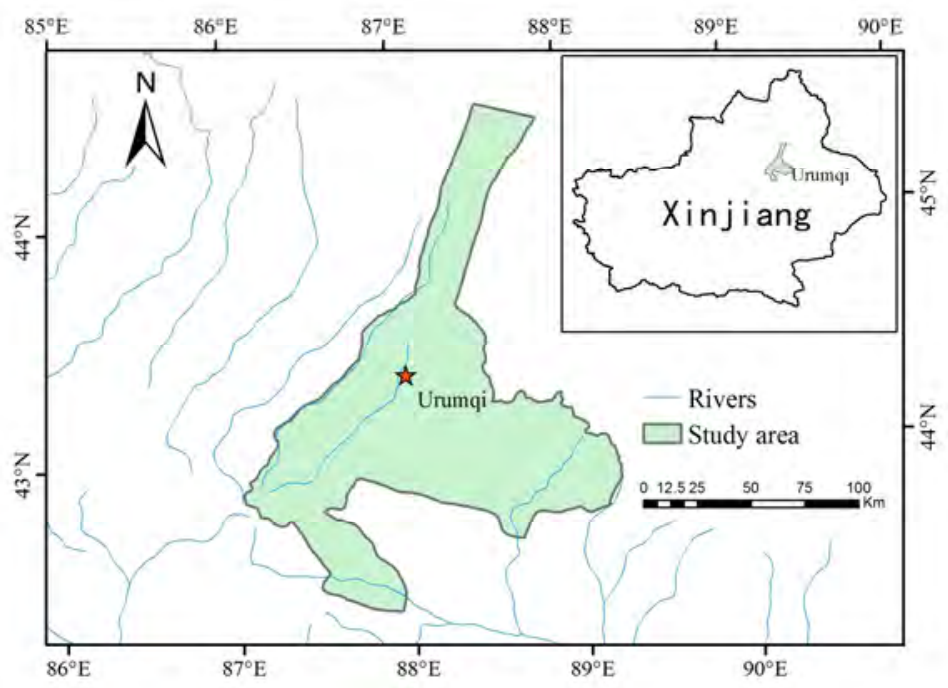

Fig. 1 Location of the study area

LUCC Products. At present, there are several available LUCC datasets, e.g. IGBP DIS Cover dataset, UMD LUCC dataset, MODIS LUCC dataset, GLC2000 dataset and CAS LUCC dataset. The data set used in this research is provided by Data Center for Resources and Environmental Sciences, Chinese Academy of Sciences (RESDC) [10]. The LUCC dataset provided by RESDC has the highest accuracy to monitor land use change in China. The data have been extensive used in fields of national land resources survey, hydrology and ecology.

In this study, the RESDC LUCC data at the late 1970s, the late 1980s, 1995, 2000, 2005, 2010 and 2015, were used to analyze land-use change in Urumqi. The land use types considered in this research are Croplands, Forest, Grasslands, Water bodies, Urban and Built-Up lands and Others.

Data Analysis. According to the LUCC products during the period from 1980 to 2015, the change amplitude and dynamic state of different types of land use in Urumqi had been statistical analysis. Base on the results, we calculated the land use transfer matrix to get conversion relations among different types of land use. Meanwhile, the spatial distribution of land use at different time in Urumqi had been draw to analyze the spatial dynamics of land use change in Urumqi during the process of urbanization.

\section{Results and Discussion}

Temporal Variation. The temporal variation of land-use cover area during 1980 to 2015 in Urumqi is shown in Table 1. Grasslands is the predominant type of land use in Urumqi, but area of Grasslands presented a continuously decreasing tendency since 1980.The area of grasslands decreased from $8846 \mathrm{~km}^{2}$ in 1980 to $8443 \mathrm{~km}^{2}$ in 2015. Croplands also constituted for a large 
proportion of Urumqi's land use, the area of croplands fluctuated in the range of $1590-1733 \mathrm{~km}^{2}$. The area of urban and built-up lands in Urumqi increased rapidly during the past four decades; the area in 2015 was about 3 times of that in 1980. The area of forest and water bodies was relatively stable during the study period.

Table 1 Changes of Land Cover Area in Different Land Types in Urumqi from 1980 to $2015\left(\mathrm{~km}^{2}\right)$

\begin{tabular}{lrrrrrrr}
\hline & 1980 & 1990 & 1995 & 2000 & 2005 & 2010 & 2015 \\
\hline Croplands & 1590 & 1702 & 1665 & 1685 & 1733 & 1723 & 1623 \\
Forest & 687 & 677 & 703 & 679 & 682 & 683 & 675 \\
Grasslands & 8846 & 8663 & 8666 & 8543 & 8485 & 8485 & 8443 \\
Water Bodies & 408 & 407 & 390 & 429 & 416 & 417 & 395 \\
Urban and Built-Up & 215 & 308 & 318 & 375 & 403 & 415 & 629 \\
Others & 3163 & 3152 & 3167 & 3198 & 3190 & 3186 & 3144 \\
\hline
\end{tabular}

The area anomaly of land use change from 1980 to 2015 is shown in Fig. 2. Each bar represents the area anomaly to the average value of one land-use type during the period from1980 to 2015 .

From 1980 to 1990, the area of croplands in Urumqi increased obviously, exceeding $100 \mathrm{~km}^{2}$; simultaneously, the reduction of grasslands area was significantly, reducing $183 \mathrm{~km}^{2}$. This period coincided with the Chinese reform and opening up policy. The regional economy in Xinjiang got rapid development, which fully responded to the governmental 8th Five-Year Plan construction policy that's focusing on the development of agriculture and agriculture associated industry [11].

Urban and Built-Up lands increased continually during 1980 to 2015; from 2010 to 2015 it's shown the most dramatic increase for $214 \mathrm{~km}^{2}$. The Government's 12th Five-Year Plan aimed to strengthen economic construction and narrow the regional economic gap. By the end of 2015, the level of urbanization in Xinjiang Uygur Autonomous Region reached 48\%. Urumqi as the capital of Xinjiang, urban construction performance is especially obvious [12].

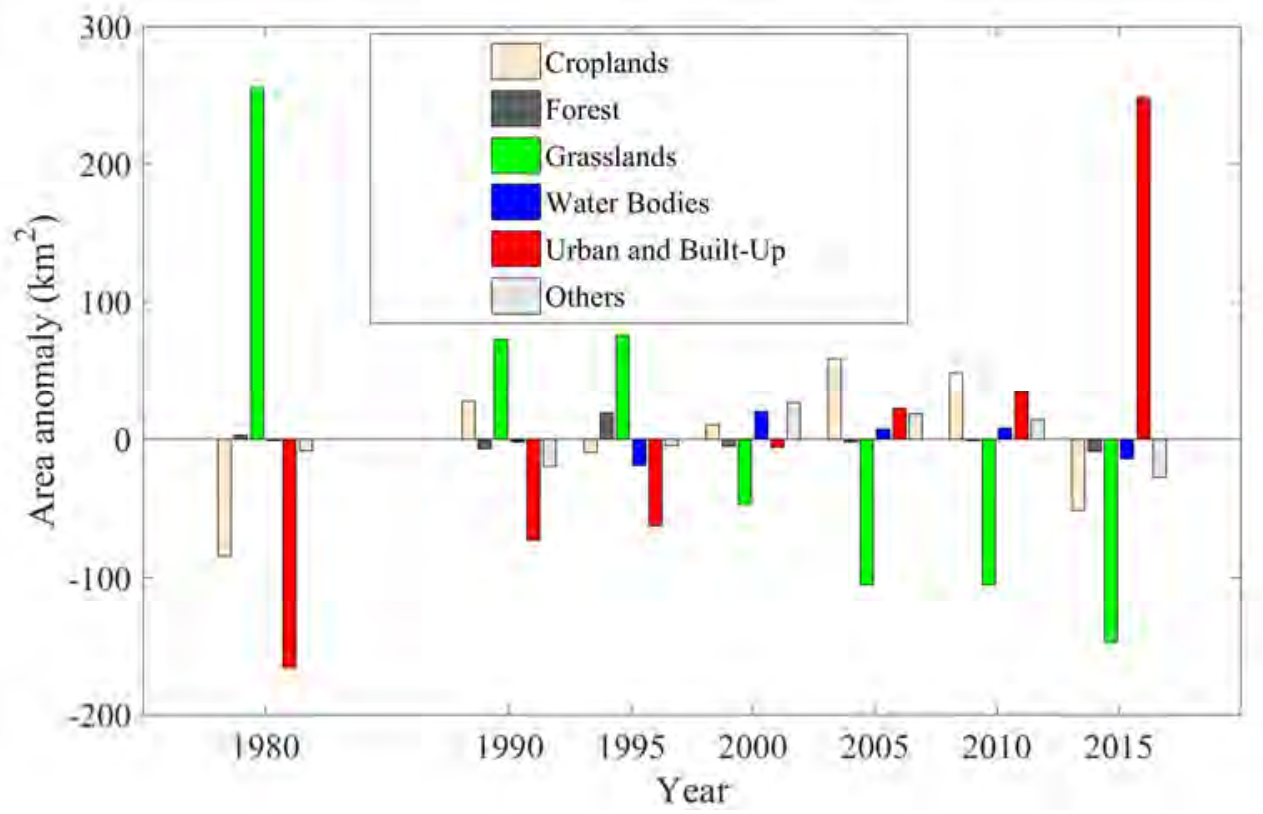

Fig. 2 Area anomaly of land use change from 1980 to 2015

To clarify the conversion relations among different land types in Urumqi over the past few decades, table 2 shows the land-use transition matrix from 1980 to 2015. The results indicated the decrease of grasslands area was mainly due to the expansion of urban and built-up lands and the reclamation of croplands. The area of grasslands converted to urban and built-up lands and croplands were $250 \mathrm{~km}^{2}$ and $194 \mathrm{~km}^{2}$, respectively. Another major source of urban and built-up lands was croplands, which converted $131 \mathrm{~km}^{2}$ to urban and built-up land from 1980 to 2015. 
Table 2 Transfer Matrix of Land Use Area in Urumqi from1980 to2015 $\left(\mathrm{km}^{2}\right)$

2015

\begin{tabular}{|c|c|c|c|c|c|c|c|}
\hline & \multicolumn{7}{|c|}{2015} \\
\hline & & Croplands & Forest & Grasslands & $\begin{array}{r}\text { Water } \\
\text { Bodies }\end{array}$ & $\begin{array}{r}\text { Urban and } \\
\text { Built-Up }\end{array}$ & Others \\
\hline & Area & 1623 & 675 & 8443 & 395 & 629 & 3144 \\
\hline Croplands & 1590 & 1386 & 3 & 57 & 1 & 131 & 12 \\
\hline Forest & 687 & 7 & 659 & 4 & 1 & 15 & 1 \\
\hline$§$ Grasslands & 8846 & 194 & 10 & 8337 & 8 & 250 & 47 \\
\hline$\approx$ Water Bodies & 408 & 6 & 1 & 19 & 376 & 2 & 4 \\
\hline Urban and Built-Up & 215 & 11 & 1 & 7 & 0 & 193 & 3 \\
\hline Others & 3163 & 19 & 1 & 19 & 9 & 38 & 3077 \\
\hline
\end{tabular}

Spatial Pattern. Major advantage of remote sensing based LUCC monitoring over statistical data is its ability to describe the spatial variation of LUCC at regional scale. The Spatiotemporal pattern of LUCC from 1980 to 2015 in Urumqi is illustrated in Fig. 3.
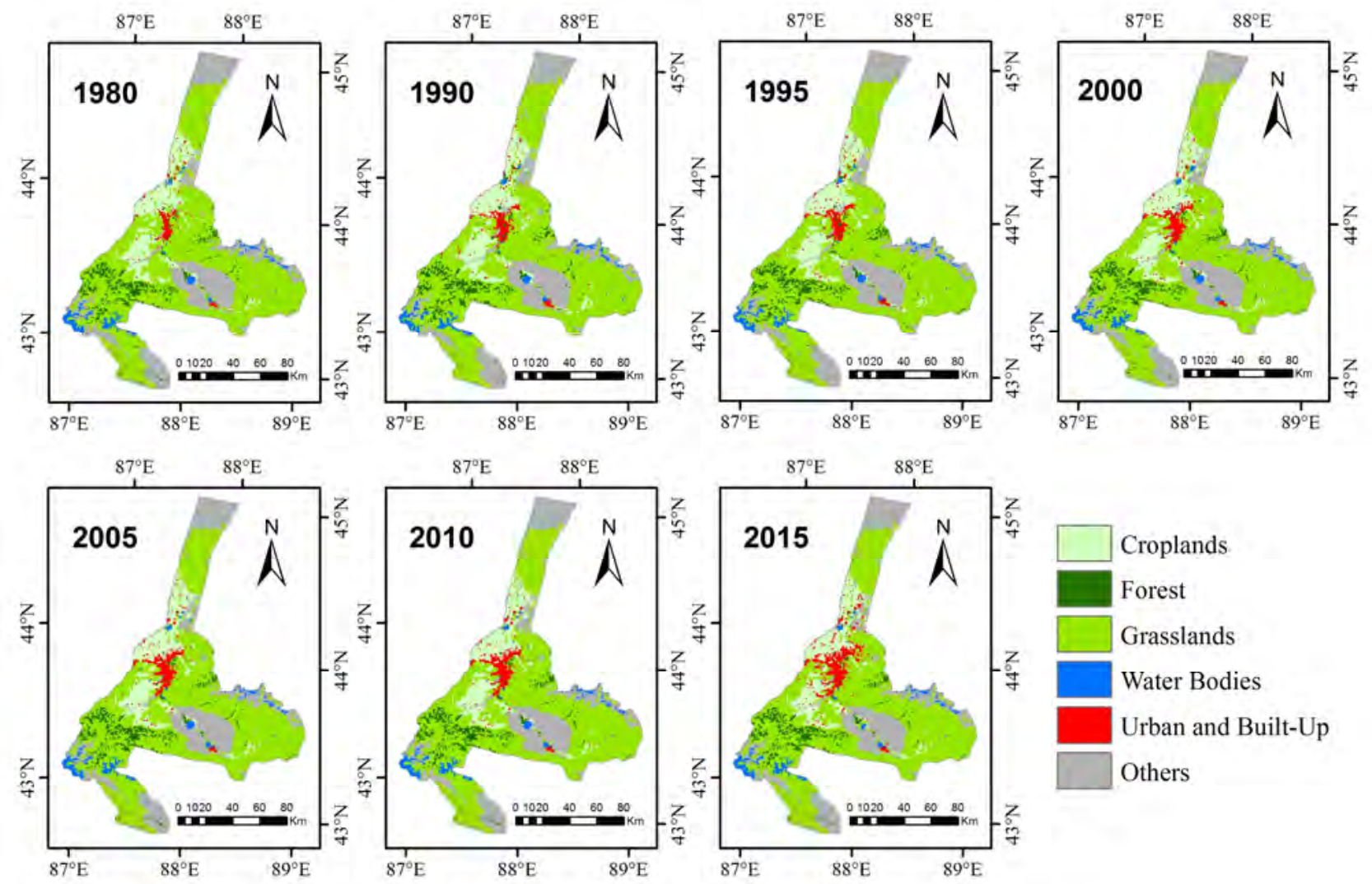

Fig. 3 The Spatiotemporal pattern of LUCC in Urumqi from 1980 to 2015

The major expansion direction of the downtown Urumqi was towards the northward. A problem that cannot be ignored is that the water area of Chaihuopu Lake decreased significantly from 2010 to 2015. Chaihuopu Lake located in the southeast of Urumqi main urban area. It's a national wetland and one of the drinking water sources of Urumqi. Due to the rapid expansion of Urumqi city, a serious shortage of urban water problems affecting the sustainable development of the city. The shrinking lake shows the urbanization leads the decline of carrying capacity for resources in city [13, 14].

\section{Conclusions}

With the acceleration of the urbanization process, Urumqi LUCC changed dramatically during 1980 to 2015. During this period, the area of grasslands in Urumqi decreased continually. The area of urban 
and built-up lands in Urumqi increased nearly three times, the downtown northward expansion trend was significant. The area of the Chaihuopu Lake located in the southern mountain region decreased remarkably from 2010 to 2015 .

\section{Acknowledgements}

This work was financially supported by National Natural Science Foundation of China (Grant No.31160114).

\section{References}

[1] He D, Liu YL, Pan ZH. Climate change and its effect on reference crop evapotranspiration in central and western Inner Mongolia during 1961-2009, Frontiers of Earth Science, Vol.7-4 (2013), p.417-428.

[2] LV Jianshu, WU Quanyuan, ZHANG Zulu, LIU Yang. Land Use Change and Ecological Security Assessment in Jining City Based on RS and GIS, Scientia Geographica Sinica, Vol.32-8(2012), p.928-935.

[3] MENG Jijun, YAN Qun, XIANG Yunyun.The optimization of ecological securit y pattern based on land use and assessment of schemes in Ordos, Journal of Desert Research, Vol.34-2(2014), p.590-596.

[4] LI Zhigang, LIU Xiaochun.The Problems of Ecological Security in China, Ecological Economy, Vol.8 (2002), p.10-13.

[5] YAO Yuan, DING Jianli, ZAO Zhengliang. Study on the land use change in Urumqi during accelerated urbanization, Journal of Arid Land Resources and Environment, Vol.26-10(2012), p.132-137.

[6] LIU Qiaoqin, WANG Shuya, LI Zijun. Effect of Urbanization on Land Use Structure in Urumqi City, Scientific and Technological Management of Land and Resources, Vol.26-3(2009), p.39-43.

[7] ZHANG Hongyuan, YANG Degang, SHI Jijin, CAI Wenchun. Analysis on Land Use Change and Driving Force in Urumqi, Journal of Arid Land Resources and Environment, Vol.21-8(2007), p.96-100.

[8] WANG Mingle, GAO Minhua. Analyzing Land Use Change and its Socio-economic Driving Factors in Urumqi, Xinjiang Agricultural Sciences, Vol. 47-11 (2010), p. 2296-2301.

[9] Information on http://xj.people.com.cn/n2/2016/0317/c188514-27950458.html

[10] Information on http://www.resdc.cn

[11] SI Zhengjia. Reform and Opening Up and Reginal Development in Xinjiang, Journal of Xinjiang Normal University (Social Sciences), Vol.29-4(2008), p.17-21.

[12] GAO Jixi. Countermeasures on Ecological Risk Prevention in Xinjiang's 12th Five-Year Plan, China Development, Vol.14-5(2014), p.14-22.

[13] LI Junli, HU Ruji, HUANG Yong. Spatial-temporal Characterstics of Chaiwopu Lake Area Change and Its Driving Factors from 1964 to 2014, Arid Zone Research, Vol.32-3(2015), p.417-427.

[14] DOU Xinying, MAO Weifeng. Analysis on the characteristics for serious degradation of the Chaihuopu wetland in Urumqi, The 32th Annual Meeting of Chinese Meteorological Society, Conference Papers,(2015). 